\title{
The Ins and Outs of Icelandic Unemployment
}

\author{
Bjarni G. Einarsson ${ }^{1}$
}

\author{
Ágrip \\ Texti ágrips
}

\begin{abstract}
This paper presents new data on Icelandic labour market flows between employment, unemployment, and inactivity, constructed from the microdata in Statistics Iceland's Labour Force Survey (LFS). An analysis of the contribution of the transition rates to the dynamics of unemployment is then performed. Assuming a fixed labour force yields results comparable to previous estimates in Iceland, with a third of the variation in steady-state unemployment explained by the job finding rate, a significant departure from what is found in Anglo-Saxon, continental European, and Nordic economies. Taking account of movements in and out of the labour force has a significant effect on contributions of transition rates to variations in steady-state unemployment, with inactivity transitions accounting for roughly a third of the variability in steady-state unemployment and a dead-even split of the remaining two-thirds between the employment-unemployment and unemployment-employment transition rates. This contribution of inactivity transitions is comparable to that in the UK, US, and Spain. The background information available in the LFS indicates that some heterogeneity exists in the contributions by gender. The participation margin is thus an important source of variation in unemployment and needs to be accounted for to fully understand the drivers of Icelandic labour market fluctuations. Furthermore, ignoring transitions in and out of the labour force generates misleading results on the relative importance of the transition rates between employment and unemployment states in Iceland.
\end{abstract}

JEL flokkun: E24, J21, J60.

Lykilord: Gross worker flows, unemployment dynamics, job finding rate, job separation rate, transition probabilities, Iceland.

1 The author would like to thank Ásgeir Daníelsson, Rannveig Sigurdardóttir, and Jósef Sigurdsson and two anonymous referees for helpful comments and discussions. This paper is a product of the collaboration agreement on economic research between the Central Bank of Iceland and Statistics Iceland. I am very grateful to Statistics Iceland for giving me access to the data and especially to Ólafur Már Sigurdsson for his assistance with the data. All remaining errors and omissions are mine. The views expressed herein do not necessarily reflect those of the Central Bank of Iceland or the University of Iceland. This research was conducted while the author was an economist at Economics and Monetary Policy, Central Bank of Iceland.

This work is licensed under a Creative Commons Attribution 4.0 License. 


\section{Introduction}

The flow of individuals between labour market states - i.e., employment, unemployment, and inactivity - determines the evolution of various aggregate labour market indicators, including employment and unemployment rates. In order to understand the dynamics of the labour market, having access to data on the transition rates between labour market states is crucial. Transition rates between labour market statuses are also at the core of the search and matching modelling framework and their measurement is thus an important stepping stone on the way to an estimated model of the Icelandic labour market.

Labour market transition rates in Iceland have previously been studied in Sigurdsson (2011), using claimant count data from the Directorate of Labour (DoL). However, such data are biased towards workers entering unemployment after job loss, as they capture only transitions of workers eligible for unemployment benefits. As such, they do not capture movements in and out of the labour force, and they necessitate a modelling framework assuming that all workers are either employed or unemployed. Indeed, an inoperative labour force participation margin is the standard modelling assumption for models of labour market fluctuations in the spirit of Mortensen \& Pissarides (1994). In fact, previous research in Iceland would seem to support such an assumption. Examining deviations from trend, Sigurdsson (2011) concludes that variations in labour force participation are secondary in explaining labour market fluctuations, and the business cycle analysis in Einarsson et al. (2013) finds that the labour force participation rate is only weakly procyclical, or even acyclical.

These studies, however, focus on the stocks of workers in each state of the labour market, which can mask transitions between states that offset each other and give the misleading result that the participation margin is not important. Krusell et al. (2012) address the issue by developing a detailed model of the labour market within a general equilibrium framework. Their central findings are that such a model accounts very well for the business cycle fluctuations in employment, unemployment and participation, which a model that shuts down the participation margin does not, and that fluctuations in employment are due mostly to transitions in and out of activity. Their results emphasise that, while the participation rate may not vary much over the business cycle, this is not evidence against its importance for aggregate fluctuations, and illustrate the importance of modelling the participation margin in order to understand the driving forces behind labour market fluctuations.

The contribution of the present paper is to present new data on labour market flows using microdata from Statistics Iceland's Labour Force Survey (LFS). Access to the microdata - i.e., individual responses - allows for matching the labour market status of individuals in consecutive quarters and thus measurement of the flow of individuals between all three labour market statuses, as the LFS covers inactive workers as well as those employed and unemployed. Using these new data for Iceland, an analysis of the contribution of the various transition rates to the dynamics of unemployment is conducted.

In order to generate results comparable to previous estimates in Iceland, the assumption that all workers are either employed or unemployed is maintained at the outset. The results of the present paper are very much in line with previous results, with about a third of the variation in steady-state unemployment is explained by the transitions from unemployment to employment for all workers. This is a very different result from that foundt in Anglo- 
Saxon economies and while somewhat closer to that found in Norway and Sweden, Iceland seems to be unusual in this regard. Furthermore, making use of the background information available in the LFS, the results indicate some heterogeneity between genders.

When taking account of movements in and out of the labour force, the steady-state approximation of measured unemployment is improved considerably relative to the twostate steady-state unemployment. Furthermore, the inclusion of inactivity transitions has a significant effect on the contribution of these rates to variations in steady-state unemployment. Inactivity transitions account for roughly a third of the variability in steadystate unemployment, with a dead-even split of the remaining two-thirds between the employment-unemployment and unemployment-employment transition rates. This result dovetails what is found for the UK and Spain. While results for the US also show that inactivity transitions account for about a third of the variations in unemployment, the split between the transition rates between employment and unemployment states is quite different, with unemployment-employment transitions accounting for almost half of the variations in unemployment. The background information provided in the LFS further reveals that there is some heterogeneity by gender.

The results of the paper support the claim of Krusell et al. (2012) for the case of Iceland. The participation margin is an important source of variation in unemployment, and it is thus important to account for transitions in and out of activity to understand fully the drivers of Icelandic labour market fluctuations. Furthermore, ignoring transitions in and out of the labour force leads to misleading results on the relative importance of the transition rates between employment and unemployment states.

The remainder of the paper is structured as follows. Section 2 discusses the Statistics Iceland Labour Force Survey microdata and the creation of the flow data. Sections 3 and 4 review the modelling frameworks and present the results for the two- and three-labour market status cases, respectively. Section 5 concludes.

\section{The Statistics Iceland Labour Force Survey}

At the beginning of 2003, Statistics Iceland began conducting a continuous labour force survey throughout the year. The year is divided into four 13-week periods, and survey results are published quarterly. The survey is conducted with a rotating panel following a $3 q-2-2 q$ system; that is, an individual enters the sample and remains in it for three consecutive quarters, then rests for two quarters but is then returned to the sample for two quarters after that. An individual is not sampled again for at least four years after first being sampled. The sample size in each quarter is 4,030 individuals, with an average participation of 3,117 individuals (a $77 \%$ response rate).

With access to the microdata, it was possible to match individual responses between quarters based on participant identifiers, from the first quarter of 2003 to the first quarter of 2015. After removing all individuals either entering the sample for the first time or rejoining the sample, an average of 2,033 respondents remain in each quarter. A further average of 317 had to be removed in each quarter due to missing responses, leaving an average of 1,716 matched responses between each quarter. Using these matched responses, it is possible to calculate the sample-weighed gross flows and transition probabilities between labour market states. The transition probabilities are then seasonally adjusted using the ratio-to-moving average method. 


\section{Two labour market states}

Although the main contribution of the paper is the creation and use of data that capture movements between all three possible labour market states, we begin by assuming a framework where all workers are either employed or unemployed. There are two main reasons for this. First, the only previous estimate of the relative importance of inflows and outflows for the dynamics of unemployment is based on claimant count data, which necessitates that the theory assume all workers to either be employed or unemployed. It is therefore an informative starting point to create compatible results using the LFS microdata in order to compare the two data sources. Second, in order to assess the importance of transitions in and out of the labour force, results based on the more standard two-state framework provide a useful benchmark.

The modelling framework assumes a continuous-time setting in which data are only available at discrete intervals. This allows for the correction of time aggregation bias (see, for example, Shimer, 2012). ${ }^{2}$ Let $t$ denote the quarter, and let $f_{t}$ denote the continuous-time transition rate from unemployment to employment during quarter $t$, or the job finding rate. The transition rate from employment to unemployment during quarter $t$, also called the job separation rate, is denoted as $s_{t}$.

When using LFS data, we observe the labour force status of each respondent at quarterly intervals. This allows for the calculation of the discrete-time job finding rate, $\hat{f}_{t}$, as the ratio of the number of individuals who were unemployed in quarter $t-1$ but are employed in quarter $t$ to the number of people who were unemployed in quarter $t-1$ and the discretetime job separation rate, $\hat{s}_{t}$, as the ratio of number of people who were employed in quarter $t-1$ but are unemployed in quarter $t$ to the number of people who were employed in quarter $t-1$. It is then possible to use the following relations between the discrete- and continuous-time rates to solve for the continuous-time job finding and job separation rates, thus correcting for time aggregation bias (see, for example, Petrongolo \& Pissarides, 2008, or Fujita \& Ramey, 2009)

$$
\begin{aligned}
& f_{t}=\frac{\hat{f}_{t}}{\hat{f}_{t}+\hat{s}_{t}}\left(-\ln \left(1-\hat{f}_{t}-\hat{s}_{t}\right)\right) \\
& s_{t}=\frac{\hat{s}_{t}}{\hat{f}_{t}+\hat{s}_{t}}\left(-\ln \left(1-\hat{f}_{t}-\hat{s}_{t}\right)\right)
\end{aligned}
$$

Given the continuous-time transition rates, changes in the unemployment rate will follow

$$
\dot{u}=(1-u) s-u f .
$$

It can be argued that, due to the size of the transition rates and assuming that they are constant during each period, unemployment practically converges to its steady state within each period (see, for instance, Petrongolo \& Pissarides, 2008, or Shimer, 2012). The unemployment rate at time $t$ can thus be approximated by

$$
u_{t}=\frac{s_{t}}{s_{t}+f_{t}}
$$

2 A possible drawback of using LFS data is that their quarterly frequency could suffer from a greater time aggregation bias than claimant count data, which are available monthly. This issue is not explored in the present paper. 
Using the LFS microdata, I construct the discrete-time transition rates $\hat{f}_{t}$ and $\hat{s}_{-} t$ assuming that every worker is either employed or unemployed. The continuous-time transition rates are then calculated according to equations (1) and (2). Having obtained the continuous-time rates, it is possible to calculate the steady-state approximation of unemployment in equation (4). Figure 1 presents seasonally adjusted measured unemployment and its steady-state approximation. Because one of the main assumptions for the validity of the decomposition of variations in unemployment presented in the upcoming equation (5) is that the steady-state approximation captures measured unemployment well, the results of the figure are somewhat disappointing. However, the correlation between the two measures peaks contemporaneously at 0.87 , slightly less than the 0.90 found in Sigurdsson (2011) using DoL data. It would thus appear that while the steady-state unemployment fails to capture the level of the measured unemployment rate, the two comove quite closely.

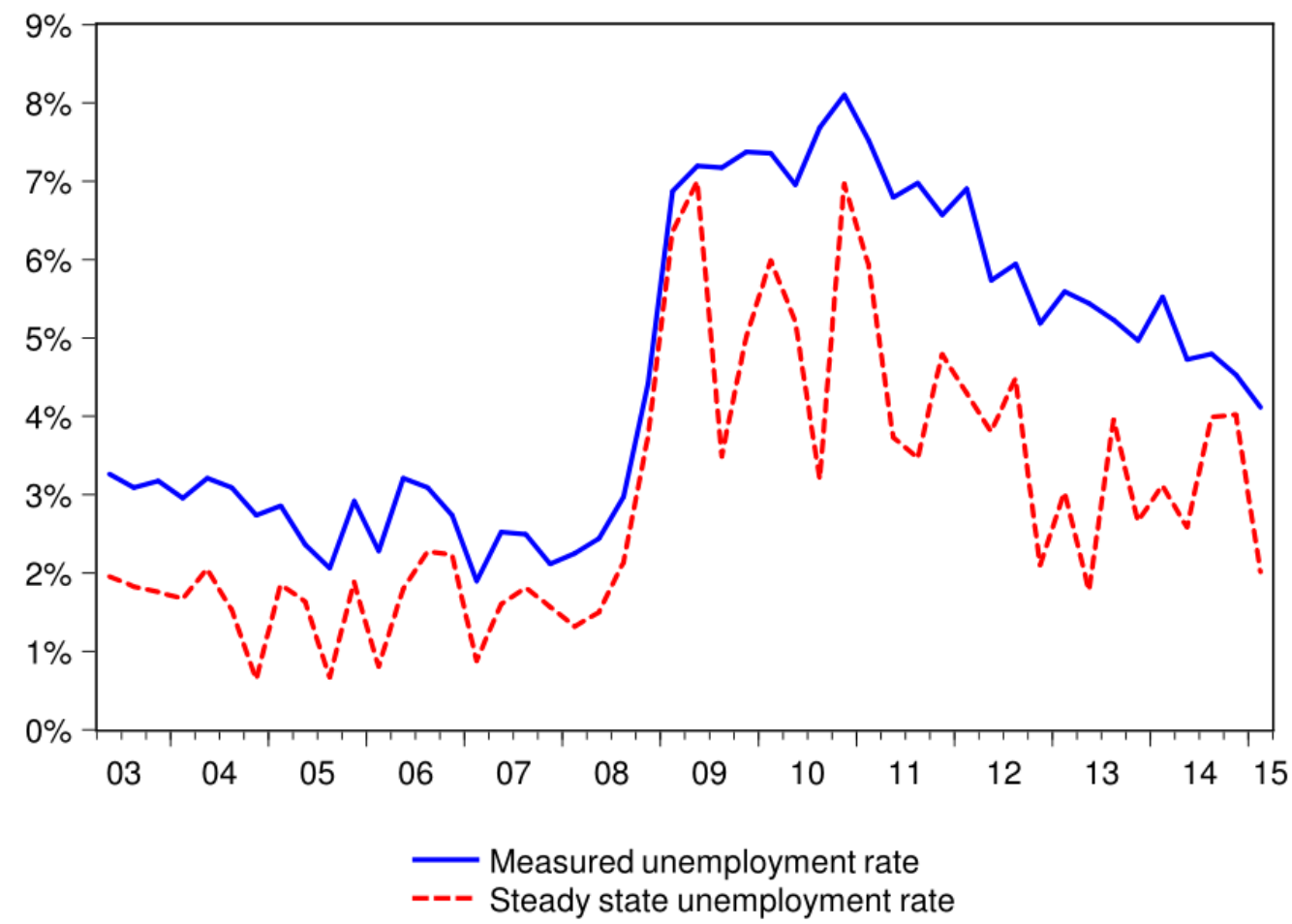

Figure 1. Measured and steady-state unemployment (two labour market states) Seasonally adjusted using the ratio-to-moving average method. Sources: Statistics Iceland, author's calculations.

In order to gain a sense of the relative contribution of the job finding and job separation rates to the development of unemployment, we can calculate hypothetical unemployment rates using equation (4), where only one of the rates is allowed to vary over time while the other is kept at its average level (e.g., $u_{t}^{f}=\bar{s}_{t} /\left(\bar{s}_{t}+f_{t}\right)$ where $\bar{x}$ denotes the average value of $x$ ). This is shown in Figure 2. A comparison of the two panels of the figure would indicate that while the job separation rate appears to explain the sharp rise in unemployment at the onset of the financial crisis in late 2008, it is the fall in the job finding rate that explains why unemployment remained high following the crisis. It also appears that decreasing unemployment after the crisis is due to the rebound in the job finding rate rather than due to 
changes in the job separation rate. This is consistent with previous evidence in Iceland and in the US (see Sigurdsson, 2011, for Iceland and Elsby et al., 2009, for the US).

Job finding rate

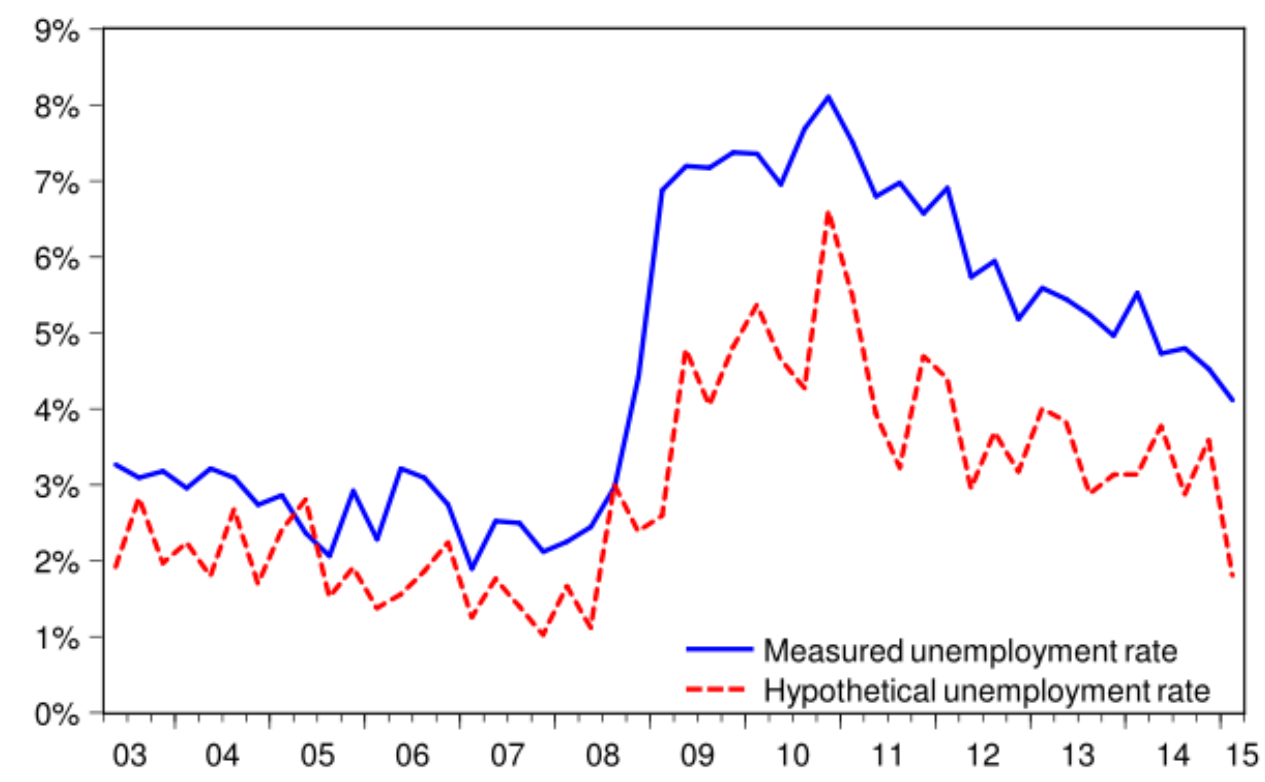

Job separation rate

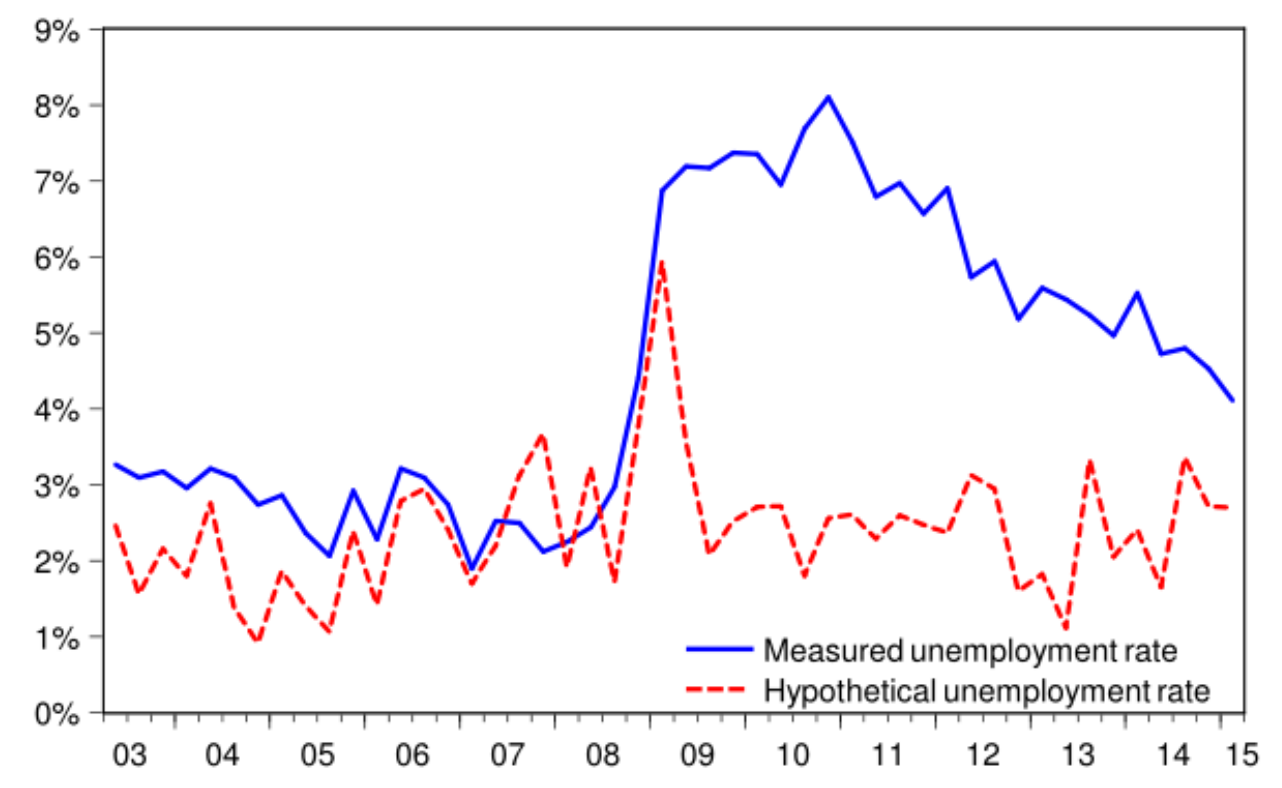

Figure 2. Measured and hypothetical paths of unemployment (two labor market states) Seasonally adjusted using the ratio-to-moving average method. Sources: Statistics Iceland, author's calculations. 
Another way of looking at the relative contribution of each rate is to look at the contribution to variations in the unemployment rate. Taking first differences of the steadystate unemployment rate in equation (4) and rearranging, changes in the unemployment rate can be decomposed as (where $\Delta x_{t} \equiv x_{t}-x_{t-1}$ ):

$$
\Delta u_{t}=\left(1-u_{t}\right) u_{t-1} \frac{\Delta s_{t}}{s_{t-1}}-u_{t}\left(1-u_{t-1}\right) \frac{\Delta f_{t}}{f_{t-1}}
$$

or, more simply,

$$
\Delta u_{t}=\Delta u_{t}^{s}+\Delta u_{t}^{f}
$$

Following Petrongolo \& Pissarides (2008) and Fujita \& Ramey (2009), the contribution of each transition rate to variations in the unemployment rate can then be calculated as

$$
\beta_{\mathrm{j}}=\frac{\operatorname{cov}\left(\Delta u, \Delta u^{j}\right)}{\operatorname{var}(\Delta u)}, j=s, f
$$

Where $\sum_{j} \beta_{j}=1$ by construction.

Table 1 presents the results for such a decomposition for all workers, and classified by gender. The results show that a third of the variation in steady-state unemployment for all workers is driven by the job finding rate, a result similar to that found using DoL data, where the job finding rate explains $29 \%$ of the variations in steady-state unemployment (see Sigurdsson, 2011). However, this is quite different from the results in Shimer (2012), who finds that the job finding rate explains roughly $3 / 4$ of the variability in steady-state unemployment for the US, or Petrongolo \& Pissarides (2008), who find that the job finding rate explains about $2 / 3$ of steady-state unemployment variability in the UK. This is further illustrated in Elsby et al. (2013) who study 14 OECD economies and find that the job finding rate explains about $85 \%$ of the variations in unemployment for the Anglo-Saxon economies. For continental European countries, however, they find the contribution of the job finding rate to be about $60 \%$, while for Norway and Sweden, the only Nordic countries in their sample, the contribution is roughly $50 \%$. The Icelandic labour market would thus seem to be at odds with international evidence in this regard.

Table 1. Contribution to variation in unemployment

The table reports the contribution of the job separation and job finding rates to changes in steady-state unemployment, calculated according to equation (7)

\begin{tabular}{llll}
\hline & All workers & Males only & Females only \\
\hline Job finding rate $\left(\beta_{f}\right)$ & 0.34 & 0.40 & 0.27 \\
Job separation rate $\left(\beta_{s}\right)$ & 0.66 & 0.60 & 0.73 \\
\hline
\end{tabular}

An examination the contribution of each rate by gender reveals a story similar to that for the entire labour force, although the job finding rate explains a somewhat greater share of the variations in male unemployment (40\%) than in female unemployment (27\%). This suggests that while the results are the same qualitatively for both genders, there is some quantitative difference in the drivers of unemployment between the genders, which is a possible future avenue for research. ${ }^{3}$

\footnotetext{
${ }^{3}$ It is, of course, also possible that this apparent difference between the genders is simply due to the short data span and that it will disappear as more data becomes available. This caveat applies to the disaggregations presented later in the paper as well.
} 


\section{Accounting for movements in and out of the labour force}

As is previously noted, the advantage of using LFS data is the possibility of relaxing the assumption that all workers are either employed or unemployed by taking into account movements in and out of the labour force.

As with the two-state theory, to account for time aggregation bias, the three-state environment is modeled in a countinuous-time setting, with data only available at discrete intervals. Following Shimer (2012), let us denote the dates at which data is available as $t \in$ $\{0,1,2, \ldots\}$, and let $\lambda_{t}^{A B}$ bet the Poisson arrival rate of a shock moving a worker from state $A \in$ $\{E, U, I\}$, where $E$ denotes employment, $U$ unemployment, and $I$ inactivity, to state $B \neq A$ at any time between $[t, t+1)$. Let us denote the accompanying continuous time Markov transition matrix as $\lambda_{-} t$; i.e., a $3 \times 3$ matrix with non-negative off-diagonal elements and columns that sum to zero. Thus we can describe the evolution of the system at time $t+\tau \in$ $[t, t+1)$, in which the state of the system can be summarised as $x(t+\tau)$, as $\dot{x}(t+\tau)=$ $\lambda_{t} x(t+\tau)$.

Given that we only have full-quarter transition probabilities, $n_{t}$, a discrete-time Markov transition matrix with non-negative entries $n_{t}^{A B}$ and columns that sum to 1 , we need a method to construct the continuous-time Markov matrix $\lambda_{t}$ uniquely. Shimer (2012) argues that if $n_{t}$ has unique, real, and positive eigenvalues, then $\lambda_{t}=p_{-} t \tilde{\mu}_{t} p_{t}^{-1}$, where $\tilde{\mu}_{t}$ is a diagonal matrix where the elements equal the natural logarithm of the eigenvalues of $n_{t}$ and $p_{t}$ is the matrix eigenvalues of $n_{t}$ (for convenience, Shimer's argument is presented in Appendix A. For more details see Shimer, 2012).

The steady-state conditions of the labour market occurs when flows in and out of employment are equal and flows in and out of unemployment are equal, or:

$$
\left(\lambda^{\mathrm{EU}}+\lambda^{E I}\right) E=\lambda^{U E} U+\lambda^{I E} I \text { and }\left(\lambda^{U E}+\lambda^{U I}\right) U=\lambda^{E U} E+\lambda^{I U} I
$$

where, $E, U$, and $I$ are the number of employed, unemployed, and inactive persons, respectively. These two equations can be solved for the steady-state unemployment rate as:

$$
\mathrm{u}_{\mathrm{t}} \equiv \frac{\lambda_{t}^{E I} \lambda_{t}^{I U}+\lambda_{t}^{I E} \lambda_{t}^{E U}+\lambda_{t}^{I U} \lambda_{t}^{E U}}{\left(\lambda_{t}^{E I} \lambda_{t}^{I U}+\lambda_{t}^{I E} \lambda_{t}^{E U}+\lambda_{t}^{I U} \lambda_{t}^{E U}\right)+\left(\lambda_{t}^{U I} \lambda_{t}^{I E}+\lambda_{t}^{I U} \lambda_{t}^{U E}+\lambda_{t}^{I E} \lambda_{t}^{U E}\right)}
$$

Having constructed the discrete-time transition matrices $n_{t}$ for all workers and classified by gender, I find that their eigenvalues are real, positive, and unique in each quarter, and it is therefore possible to correct for time aggregation bias using the method suggested by Shimer (2012). Figure 3 presents the steady-state unemployment rate based on all workers. The steady-state unemployment rate based on all three labour market states approximates the level of measured unemployment much more closely than the steady-state unemployment rate based only on two labour market states, with the correlation between the steady state and measured unemployment rates peaking contemporaneously at 0.91 . The three-state steady-state unemployment rate thus provides a better approximation to measured unemployment than the steady state based on two labour market states. 


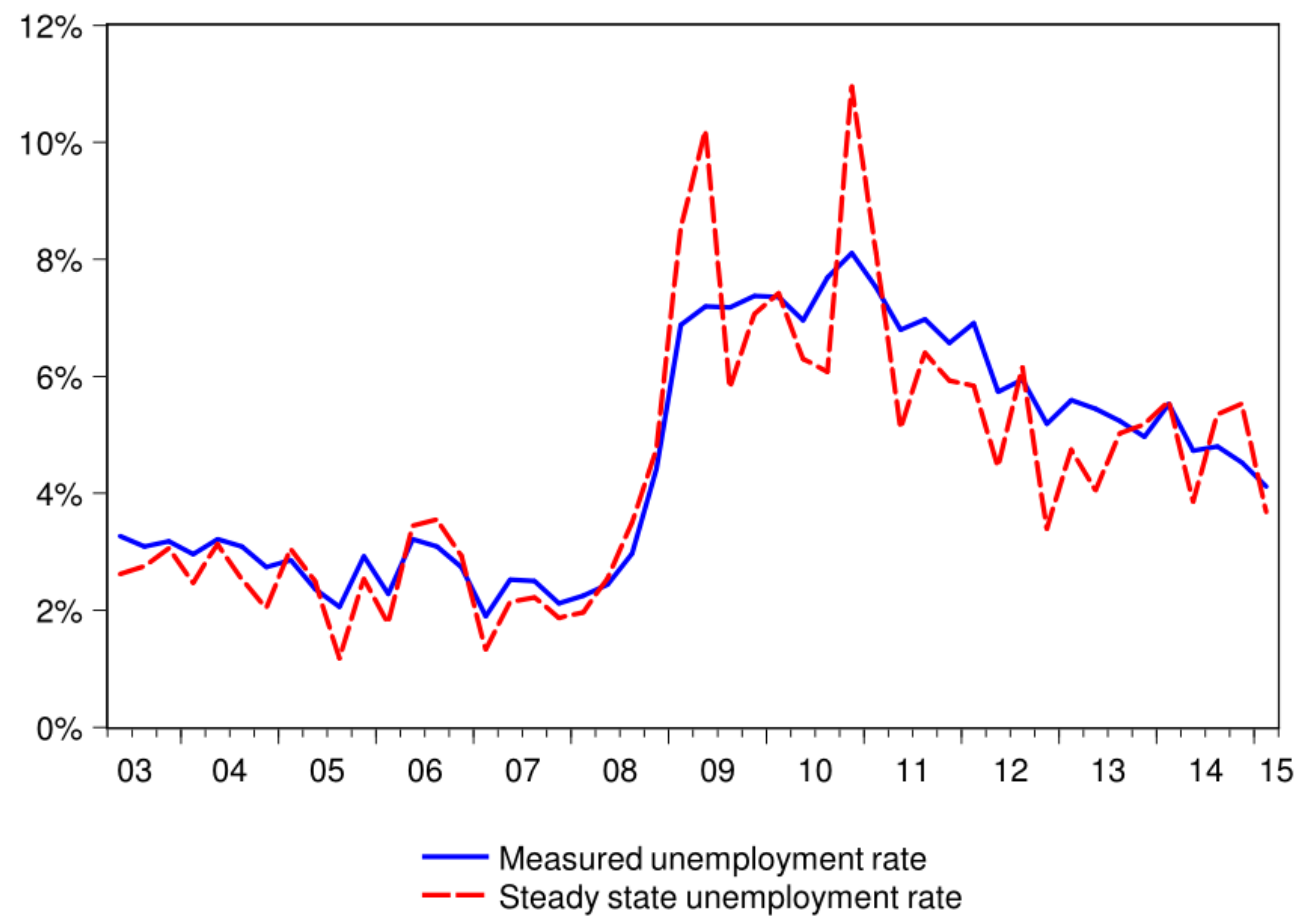

Figure 3. Measured and steady-state unemployment (three labour market states) Seasonally adjusted using the ratio-to-moving average method. Sources: Statistics Iceland, author's calculations.

It can be useful to compare the job finding and separation probabilities calculated in the previous section, with their three-state counterparts, the unemployment-employment and employment-unemployment transition rates. Figure 4 presents such a comparison where the rates have been transformed into full-quarter transition probabilities using the transformation $X_{t}=1-e^{x_{t}}$, where $x_{t}$ is the continuous-time rate and $X_{t}$ the full-quarter transition probability. As is evident from the figure, the job finding and unemploymentemployment transition probabilities move very closely, with the contemporaneous correlation between them exceeding 0.99. The unemployment-employment transition probability is an average of 4 percentage points lower than the job finding probability, however, while the two probabilities have almost identical volatility. A similar story emerges when comparing the job separation probability and the employment-unemployment transition probability; the contemporaneous correlation again exceeds 0.99 and the volatility of the series is virtually identical. The average difference between the two is much lower than for the previous pair, though, with the employment-unemployment transition probability less than 0.1 percent age points less than the job separation probability, on average. 

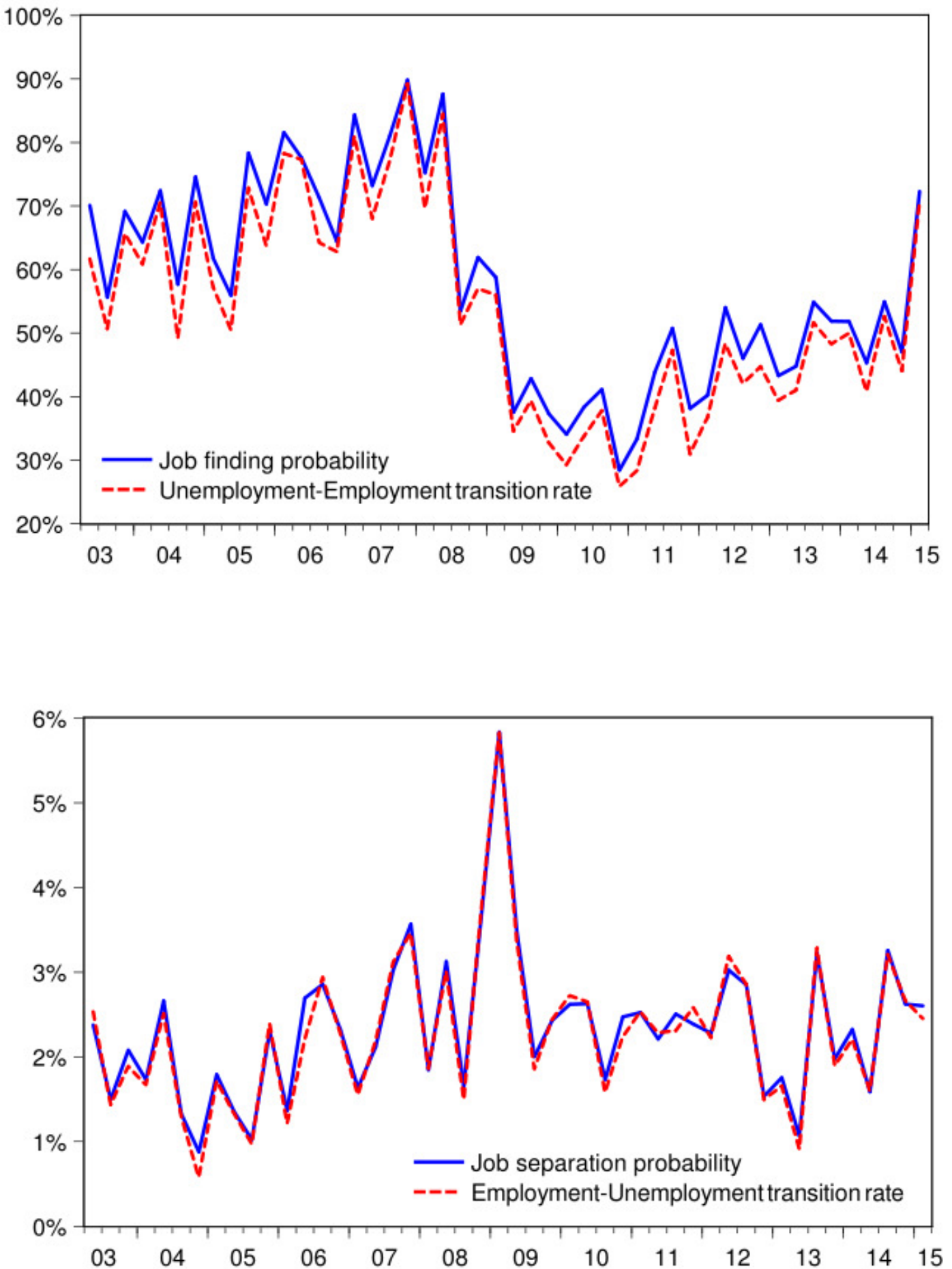

Figure 4. Job finding and job separation probabilities and UE and EU transition rates Full-quarter transition probabilities calculated as $X_{t}=1-e^{X_{t}}$ where $x_{t}$ is the continuous-time rate. Source: Author's calculations.

As in the two-state case, to gain insight into the contribution of each transition rate to the evolution of unemployment, it is illustrative to calculate hypothetical paths of unemployment based on each of the three-state transition rates. This is presented, along with seasonally adjusted measured unemployment, in Figure 5. 

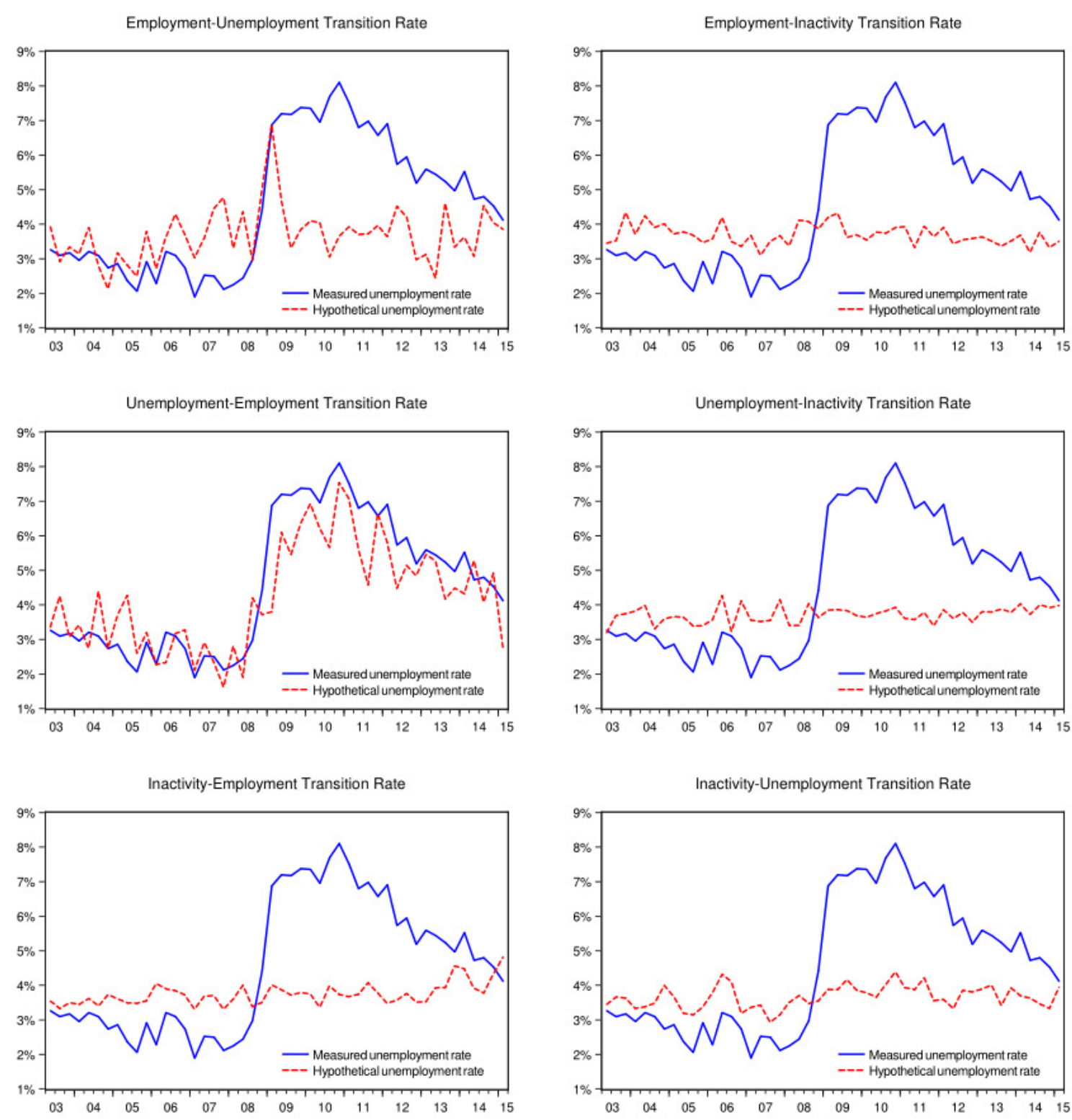

Figure 5. Measured and hypothetical paths of unemployment (three labour market states)

Seasonally adjusted using the ratio-to-moving average method. Sources: Statistics Iceland, author's calculations.

A story similar to that in the two-state case emerges, with a spike in the employmentunemployment transition rate accounting for the sharp rise in unemployment following the financial crisis, in late 2008 to early 2009, with the hypothetical path based on the unemployment-employment rate following the evolution of the measured unemployment rate most closely both before and after the crisis and the hypothetical paths based on inactivity transitions remaining fairly flat throughout the sample period. In fact, the contemporaneous correlation between seasonally adjusted measured unemployment and the hypothetical rate based on the unemployment-employment transition rate is 0.88 , far outpacing the second-highest contemporaneous correlation of 0.56 between measured unemployment and the inactivity-unemployment transition rate, and the average difference 
between the two is only 0.3 percentage points (although the standard deviation of the difference is just under $1 \%$ ).

Again, it is also informative to look at the contribution of the transition rates to variations in steady-state unemployment. Following Petrongolo \& Pissarides (2008), equation (9) can be rearranged as

$$
\mathrm{u}_{\mathrm{t}} \equiv \frac{\lambda_{t}^{E U}+\frac{\lambda_{t}^{I U}}{\lambda_{t}^{I U}+\lambda_{t}^{I E}} \lambda_{t}^{E I}}{\lambda_{t}^{E U}+\frac{\lambda_{t}^{I U}}{\lambda_{t}^{I U}+\lambda_{t}^{I E}} \lambda_{t}^{E I}+\lambda_{t}^{U E}+\frac{\lambda_{t}^{I E}}{\lambda_{t}^{I U}+\lambda_{t}^{I I}} \lambda_{t}^{U I}}
$$

And written as

$$
\mathrm{u}_{\mathrm{t}} \equiv \frac{\lambda_{t}^{E U}+i_{0, t}}{\lambda_{t}^{E U}+i_{0, t}+\lambda_{t}^{U E}+i_{1, t}}
$$

where $i_{0, t} \equiv \lambda_{t}^{I U} \lambda_{t}^{E I} /\left(\lambda_{t}^{I U}+\lambda_{t}^{I E}\right)$ and $i_{1, t} \equiv \lambda_{t}^{I E} \lambda_{t}^{U I} /\left(\lambda_{t}^{I U}+\lambda_{t}^{I E}\right)$ which, as they note, could loosely be interpreted as the contributions to equilibrium unemployment of inactivity transitions to and from unemployment, respectively.

If we further define $s_{t} \equiv \lambda_{t}^{E U}+i_{0, t}$ and $f_{t} \equiv \lambda_{t}^{U E}+i_{1, t}$ equation (11) becomes identical to equation (4); thus the decomposition in equation (5) holds. Taking first differences of the newly defined $s_{t}$ and $f_{t}$ gives:

$$
\frac{\Delta s_{t}}{s_{t-1}}=\frac{\Delta \lambda_{t}^{E U}}{\lambda_{t-1}^{E U}+i_{0, t-1}}+\frac{\Delta i_{0, t}}{\lambda_{t-1}^{E U}+i_{0, t-1}}
$$

and

$$
\frac{\Delta f_{t}}{f_{t-1}}=\frac{\Delta \lambda_{t}^{U E}}{\lambda_{t-1}^{U E}+i_{1, t-1}}+\frac{\Delta i_{1, t}}{\lambda_{t-1}^{U E}+i_{1, t-1}}
$$

the contributions of the total inflow and outflow rates to unemployment can be decomposed into contributions from flows between employment and unemployment and the inactivity flows. Equation (7) can therefore be used to calculate the contributions of each of these terms to variations in unemployment.

Using equations (5), (7), (12), and (13), Table 2 presents the results of such a calculation for all workers and classified by gender. Interestingly, what emerges differs significantly from the two-state case. While the unemployment-employment transition rate explains about a third of the volatility of steady-state unemployment, just as its two-state counterpart the job finding rate, the employment-unemployment now only explains about a third of the variation as well, with the remaining third being explained by the inactivity transitions. This result is very similar to that found in Petrongolo \& Pissarides (2008) for both the UK and Spain, where, as in the present paper, the inactivity transitions contribute about a third, with the remaining two-thirds split between the transition rates between unemployment and employment, roughly equally split for Spain and a dead-even split for the UK, as is the case for Iceland. Using data for the US, Shimer (2012) finds that while the inactivity transitions account for about a third of the variation in steady-state unemployment, as in the UK, Spain, and Iceland, the split between the transition rates between employment and unemployment is rather different, with almost $50 \%$ of the variation contributed by the unemploymentemployment transition rate and roughly $20 \%$ by the employment-unemployment transition rate. 
Table 2. Contribution to variation in unemployment

The table reports the contribution of four transition rates to changes in steady-state unemployment, calculated according to equations (5), (7), (12), and (13). Columns may not sum to unity due to rounding errors.

\begin{tabular}{llll}
\hline & All workers & Males only & Females only \\
\hline Employment-unemployment $\left(\lambda^{E U}\right)$ & 0.33 & 0.39 & 0.27 \\
"Inactivity-Unemployment“ $\left(i_{0}\right)$ & 0.21 & 0.19 & 0.17 \\
Unemployment-Employment $\left(\lambda^{U E}\right)$ & 0.33 & 0.24 & 0.44 \\
„Unemployment-Inactivity“ $\left(i_{1}\right)$ & 0.14 & 0.18 & 0.12 \\
\hline
\end{tabular}

When looking at the contributions by gender, two different stories emerge. While the inactivity transition rates account for about a third in both cases, the relative importance of the transition rates between employment and unemployment essentially get flipped. While the employment-unemployment rate explains 39\% for males and the unemploymentemployment rate $24 \%$, the contribution for females are $27 \%$ and $44 \%$, respectively. Thus we can conclude that job losses have more impact on male unemployment while moving out of unemployment through finding a job has a greater effect on female unemployment. The relative importance of the employment-unemployment and unemployment-employment transition rates is interestingly roughly the same 60:40 split as in the two-state case for males, while the relative importance for females is a 40:60 split as opposed to the 70:30 split in the two-state case.

\section{Conclusion}

The present paper presents new data on labour market flows using microdata from Statistics Iceland's Labour Force Survey. Access to the microdata - i.e., individual responses - allows for matching the labour market status of individuals in consecutive quarters and gives a measure of the flow of individuals between all three labour market statuses, as the LFS covers inactive workers as well as those employed and unemployed. Using these new data for Iceland, an analysis of the contribution of the various transition rates to the dynamics of unemployment is conducted.

As a first step, and to obtain results that can be compared with previous results for Iceland using claimant count data, the assumption that all workers are either employed or unemployed was maintained. The results of the present paper dovetail with previous results, in that about a third of the variation in steady-state unemployment is explained by the transitions from unemployment to employment for all workers. This is very different from what is found in Anglo-Saxon economies and, while somewhat closer to the results for Norway and Sweden, Iceland seems to be at unusual in this regard. Making use of the background information available in the LFS, the results indicate, however, that the unemployment-employment transition plays a greater role in explaining variations for men than for women ( $40 \%$ and $27 \%$ respectively), indicating some heterogeneity between the driving forces behind male and female unemployment.

The modelling framework was then expanded to include movements in and out of the labour force. The steady-state approximation of measured unemployment is improved considerably by the inclusion of transitions in and out of inactivity relative to the steady-tate approximation based on two labour market states. While the estimated job finding and job separation rates are almost identical to their three-state counterparts, the unemployment- 
employment and employment-unemployment transition rates, the inclusion of inactivity transitions has a significant effect on the contributions of these rates to variations in steadystate unemployment. Inactivity transitions account for roughly a third of the variability in steady-state unemployment, with a dead-even split of the remaining two-thirds between the employment-unemployment and unemployment-employment transition rates. This result dovetails what is found for the UK and Spain. While results for the US also show that inactivity transitions account for about a third of the variations in unemployment, the split between the transition rates between employment and unemployment states is different, with unemployment-employment transitions accounting for almost half of the overall variations in unemployment. Again, looking at the contributions by gender reveals some heterogeneity. While the inactivity transitions still account for about a third for both genders, the importance of the transitions between employment and unemployment are flipped. The employment-unemployment transition accounts for almost $40 \%$ for men and the unemployment-employment transition for about $25 \%$, while for women the contributions are $27 \%$ and $44 \%$, respectively.

The results of the paper support the claim of Krusell et al. (2012) for the case of Iceland. The participation margin is an important source of variation in unemployment, and it is thus important to account for transitions in and out of activity to understand fully the drivers of Icelandic labour market fluctuations. Furthermore, ignoring transitions in and out of the labour force generates misleading results on the relative importance of the transition rates between employment and unemployment states.

From a policy perspective, the results of the paper and the new data are valuable for monitoring the development of unemployment and its determinants, and more generally, for monitoring the status of the labour market. From a research perspective, they should serve as a spark for further research into the stylised facts of the Icelandic labour market which estimated models should be able to replicate, be it the cyclical properties of the transition rates, exploration of the apparent differences between the various sub-groups, or better placement of the Icelandic labour market on the international spectrum; e.g., by comparison of the transition probabilities. Another avenue of research could be an exploration of whether these transition rates are of value in forecasting the aggregate labour market variables (see, for instance, Barnichon \& Nekarda, 2013). A further potential avenue, made possible by taking account of the participation margin, could be to examine the determinants of the labour force participation rate over the business cycle and their contributions to variations in participation. Finally, the data provide the means to estimate, or a guide to the calibration of, various labour market model parameters. These are all left as the subject of future research.

\section{References}

Barnichon, R. \& Nekarda, C. J. (2013). The ins and outs of forecasting unemployment: Using labor force flows to forecast the labor market. Federal Reserve Board Finance and Economics Discussion Series no. 2013-19.

Einarsson, B. G., Emilsson, G., Haraldsdóttir, S. J., Pétursson, T. G., \& Sveinsdóttir, R. B. (2013). On our own? The Icelandic business cycle in an international context. Central Bank of Iceland Working Paper no. 63.

Elsby, M. W., Michaels, R., \& Solon, G. (2009). The ins and outs of cyclical unemployment. American Economic Journal: Macroeconomics, 1(4), 84-110. 
Elsby, M. W. L., Hobijn, B., \& Sahin, A. (2013). Unemployment dynamics in the OECD. Review of Economics and Statistics, 95(2), 530-548.

Fujita, S. \& Ramey, G. (2009). The cyclicality of separation and job finding rates. International Economic Review, 50(2), 415-430.

Krusell, P., Mukoyama, T., \& Sahin, R. R. A. (2012). Is labor supply important for business cycles? National Bureau of Economic Research NBER Working Paper, no. 17779.

Mortensen, D. T. \& Pissarides, C. A. (1994). Job creation and job destruction in the theory of unemployment. Review of Economic Studies, 61, 397-415.

Petrongolo, B. \& Pissarides, C. A. (2008). The ins and outs of European unemployment. American Economic Review: Papers \& Proceedings, 98(2), 256-262.

Shimer, R. (2012). Reassessing the ins and outs of unemployment. Review of Economic Dynamics, 15, 127-148.

Sigurdsson, J. (2011). Unemployment dynamics and cyclical fluctuations in the Icelandic labour market. Central Bank of Iceland Working Paper no. 56. 


\section{Appendix A Correcting for time aggregation bias}

Shimer (2012) presents the following way to construct a continuous-time Markov transition matrix $\lambda_{t}$ from a discrete-time Markov transition matrix $n_{t}$. Begin with the related question of what happens if period $t$ is divided into $1 / \Delta$ subperiods of equal length. The transition matrix for each subperiod is $n_{t, \Delta}$ while the transition matrix for the entire period remains the same.

If $\mu_{t, \Delta}$ is a diagonal matrix of eigenvalues of $n_{t, \Delta}$ and $p_{t, \Delta}$ the associated matrix with eigenvectors in columns then, if the eigenvalues are distinct, the diagonalisation $n_{t, \Delta}=$ $p_{t, \Delta} \mu_{t \Delta} p_{t, \Delta}^{-1}$ is possible. Matrix multiplication thus implies that $n_{t}=p_{t, \Delta} \mu_{t \Delta}^{1 / \Delta} p_{t, \Delta}^{-1}$ and thus that the eigenvalues of $n_{t}$ are the eigenvalues of $n_{t, \Delta}$ raised to the power $1 / \Delta$ while the eigenvectors are the same.

The question now becomes whether the reverse is true; i.e., whether it is possible to construct $n_{t, \Delta}$ from $n_{t}$. Shimer (2012) claims that the answer is yes if the eigenvalues of $n_{t}$ are all unique, real, and nonnegative. To construct $n_{t, \Delta}$ from $n_{t}$, let $n_{t}=p_{t, \Delta} \mu_{t \Delta}^{\Delta} p_{t, \Delta}^{-1}$, where $\mu_{t}^{\Delta}$ is the diagonal matrix of eigenvalues of $n_{t}$ raised to the power $\Delta$ and $p_{t}$ the matrix of eigenvectors. Shimer (2012) furthermore claims that, if the eigenvalues of $n_{t, \Delta}$ are also unique, real, and nonnegative, this transformation is unique.

Now note that the continuous-time Markov transition matrix $\lambda_{t}$ is simply the limit of $\left(n_{t, \Delta}-I\right) / \Delta$, where $I$ is the identity matrix. Thus the fact that $\lim _{\Delta \rightarrow 0}\left(\varepsilon^{\Delta}-1\right) / \Delta=\ln \varepsilon$ gives the main result. If $n_{t}$ has unique, real, and positive eigenvalues, then $\lambda_{t}=p_{t} \tilde{\mu}_{t} p_{t}^{-1}$, where $\tilde{\mu}_{t}$ is a diagonal matrix with elements equal to the natural logarithm of the eigenvalues of $n_{t}$ and $p_{t}$ is the associated matrix of eigenvalues of $n_{t}$ and thus necessarily also of $\lambda_{t}$. 